\title{
Evaluation of Knowledge, Attitude and Practice of Rational use of Medicine Among Interns and Resident Doctors in a Tertiary Care Teaching Hospital
}

\author{
Ganesh Dakhale ${ }^{1 *}$, Sonali Pimpalkhute, ${ }^{2}$ Chaitali Bajait, ${ }^{2}$ Latesh Raghute ${ }^{2}$ \\ 'Professor in Pharmacology, Govt. Medical College, Nagpur, INDIA. \\ 2Department of Pharmacology, Govt. Medical College, Nagpur, INDIA.
}

\begin{abstract}
Objective: To evaluate and compare knowledge, attitude and practice of rational use of medicine among post graduate students and interns in a tertiary care teaching hospital. Material and Method: This was a questionnaire based study which included 100 post graduate students from different specialties and 100 intern students of a tertiary-care teaching hospital. Results: Ninety six percent respondents were aware about the term RUM and $95 \%$ practiced it, only $10.5 \%$ had NLEMI available at their work place and $48 \%$ clinicians were able to correctly name the parts of the prescription slip. 87.5\% respondents were aware about EM and 85\% prescribed them. Percentage of respondents prescribing EM and practicing RUM was significantly higher in male than in females. $(p<0.0001)$. Though $32 \%$ respondents practiced ' $p$ ' drug concept only $15.5 \%$ were aware about STEP criteria. Conclusion: In the present study majority of respondents
\end{abstract}

were aware about most of the issues concerned with RUM addressed in the questionnaire which seems to be a positive finding. But being future prescribers all of them need to have correct knowledge about all the issues addressed.

Key words: Essential medicine, P-drug, KAP study.

Correspondence :

Dr. Ganesh Dakhale,

Professor in Pharmacology Govt. Medical College,

Nagpur-3, INDIA.

E-mail: gndakhle@rediffmail.com

DOI: $10.5530 /$ jyp.2016.2.10

\section{INTRODUCTION}

According to a report by World Health Organization (WHO), 50\% of all medicines are prescribed, dispensed or sold incorrectly, while $50 \%$ of patients fail to take their medicines satisfactorily. ${ }^{1}$ Rational use of medicine (RUM) as defined by WHO requires that patients receive medications appropriate to their clinical needs, in doses that meet their own requirements, for an adequate period of time, and at the lowest cost to them and their community. ${ }^{2}$ Increase in irrational use of medicines is due to factors such as misleading/false beliefs, inadequate knowledge on part of the consumers and prescribing pressures, professional, profit driven approach of prescribers, lucrative promotional activities by pharmaceutical industry and lack of enforcement of regulations by regulatory authorities. $^{3}$

Essential medicines, a corner stone of RUM defined as those that satisfy the health care needs of the majority of a population. This concept was defined in 1975 by the WHO as a major step towards promoting RUM. ${ }^{4}$ The Ministry of Health, Government of India revised the National List of Essential Medicines of India (NLEMI 2011) in June 2011. The NLEMI 2011 contains 348 medicines. ${ }^{5}$ Essential medicines lists have been shown to improve the quality and cost-effectiveness of health care delivery when combined with proper procurement policies and good prescribing practices. ${ }^{6}$ P-drug concept was introduced to boost the cause of RUM. The idea was to make physicians familiar with some personal drugs chosen from NLEMI based on safety, efficacy, suitability and cost.? The first step to correct irrational use of medicines is to measure it. To address the problem of irrational use of medicines, the health planners need specific information on the type of irrationality been practiced so that appropriate, effective and feasible strategies can be chosen. Various studies have evaluated the perception of RUM among different stakeholders viz; nurses, pharmacy students, pharmacists, prescribers. ${ }^{8}$
A medical student enters practice during internship. Internship is the period where students after passing final MBBS examination prescribe medicines and offer patient care under the guidance of teachers. During this period they should form habit of correct method of prescribing right drugs in right doses. Rational prescription writing is a skill which should be mastered at the earliest. At the start of clinical training most medical students find that they don't have a very clear idea of how to prescribe a drug for their patients or what information they need to provide. Post graduate students start prescribing drugs usually in the first year. Their attitude toward good prescribing, rational drug use is of utmost importance as they constitute the future generation of doctors. Most often students are only expected to copy the prescribing behavior of their clinical teachers, or existing standard treatment guidelines, without explanation as to why certain treatments are chosen. ${ }^{9}$ Though majority of students recognize the importance of RUM, most of them have not been able to apply regularly this knowledge in their daily medical practice. ${ }^{6}$ In addition, this is the time when he may get in touch with medical representatives who try to change their prescribing habits using various techniques of marketing and at times by offering free samples, gifts and medical literature. It is thus logical to assume that our efforts to promote RUM should also begin at this period. The concept of RUM was incorporated in practical curriculum of 2nd year MBBS pharmacology teaching by Maharashtra university of health sciences, Nashik in 2000 to make student familiar with RUM. In our institute, orientation programme is conducted for interns where a lecture on RUM is included. With this above mentioned fact, this study was planned to evaluate and compare knowledge, attitude and practice of rational use of medicine among post graduate students and interns in a tertiary care teaching hospital. 


\section{MATERIALS AND METHODS}

Two hundred subjects participated in this study approved by Institutional Ethics Committee. This was a questionnaire based study which included 100 post graduate students from different specialties and 100 intern students of a tertiary-care teaching hospital. Self-developed, pre-validated questionnaire consisting of both open-ended and close-ended items were given to fill up after explaining the nature and purpose of the study. Written informed consent was obtained from each participant. Informed consent was voluntary and freely given. The questionnaire was first pre-tested in five respondents and appropriate modifications done. Post graduate students and interns working in pre-clinical and paraclinical disciplines and those who refused to give written consent were excluded from the study. In all, the questionnaire had 17 questions related to the demographic profile, EM, RUM, concept of P-drugs, and sources of drug information. At the end of the study, all the data was pooled and expressed as counts and percentages. Univariate analysis, which explores each variable in a data set separately, was carried out by using the fisher's exact test. Graph pad prism software version 5.01 was used to analyze data. A probability value of $<0.05$ was considered significant.

\section{RESULTS}

Out of 200 respondents, 74 were men and 126 women with age ranging from 21 to 30 years. Fifty percent respondents were junior residents pursuing their post graduation after MBBS in any of the clinical disciples whereas $50 \%$ were interns who have just passed the final MBBS exam (Table 1).

Although 96.5\% respondents were aware about the term RUM and $95 \%$ practiced it, only $10.5 \%$ had NLEMI available at their work place and $48 \%$ clinicians were able to name the parts of the prescription slip correctly. (Table 2) Though 32\% respondents practiced 'p' drug concept, only $15.5 \%$ were aware about STEP criteria. (Table 2) Nearly thirty four percent respondents prescribed drugs by generic names while majority of respondents (61.5\%) prescribed by both generic as well as brand names. (Table 3). Eighty eight percent respondents were aware about EM and $85 \%$ prescribed them. Percentage of respondents prescribing EM and practicing RUM was significantly higher in male than in females. $(\mathrm{p}<0.0001)$. (Table $3 \& 4)$ Eighty six percent of respondents were always aware of the adverse effects, interactions, and contraindication of the drugs they prescribe. Surprisingly majority of respondents (92.5\%) relied on information from standard text books, $70 \%$ refer drug indices, $61.5 \%$ use internet whereas only $12 \%$ respondents read review articles in journals and $23.5 \%$ rely on MR for obtaining information about various drugs and regimens (Figure 1).

\section{DISCUSSION}

The present study evaluates knowledge, attitude and practice about RUM in interns and post graduate medical students working in a tertiary care teaching hospital. Training in rational use of medicines is more likely to be effective if it takes into consideration outlook and expertise and is targeted to the prescribing requirements in future. ${ }^{7}$ This study would take into consideration existing knowledge and understanding of interns and post graduate students about various issues concerned with RUM and would guide us in training them better in our institute. Hence, assessing knowledge of RUM among them in such set-up would be helpful in promoting RUM and improving health care services. In the present study, majority of respondents were aware about most of the issues concerned with RUM addressed in the questionnaire which seems to be a positive finding. But being future prescribers, all of them need to have correct knowledge about all the issues addressed. Majority of respondents seem to be aware of the concept of essential medicine since it is an old concept. Surprisingly, $83.5 \%$ of the respondents prescribed essential medicine frequently despite of not having NLEMI at their workplace.

Table 1: Demographic characteristics of respondents

\begin{tabular}{lc}
\hline \multicolumn{1}{c}{ Characteristics } & Percentage \\
\hline Gender (M:F) & $63: 37$ \\
Designation & \\
Interns & 50 \\
Residents & 50 \\
\hline $\mathrm{N}=200$. &
\end{tabular}

$\mathrm{N}=200$.

Table 2: Knowledge about RUM ( $n=200)$

\begin{tabular}{lcc}
\hline & \multicolumn{1}{c}{ Questions/statements } & \multicolumn{2}{c}{$\begin{array}{c}\text { Percentage of } \\
\text { respondents }\end{array}$} \\
\cline { 2 - 3 } & Yes & No \\
\hline - Are you aware of the term essential drugs? & 87.5 & 12.5 \\
- Are you aware that now the term used is essential medicines? & 76 & 24 \\
- Do you have the National Model Essential Drug List at your work place? & 10.5 & 89.5 \\
- Do you know the number of drugs included in Indian EML If yes specify & 4.0 & 96 \\
- Do you know the number of fixed dose combination included in EML & 0 & 100 \\
- Are you aware of the term RUM? & 96.5 & 3.5 \\
- Can you name the parts of a prescription? & 48 & 52 \\
- Are you always aware of the ingredients of the drug you prescribe? & 96.5 & 3.5 \\
- Are you aware of the term P-drugs? & 32 & 68 \\
- Are you aware of STEP criteria for selection of P-drug? & 15.5 & 84.5 \\
- Are you aware of advantages of using P-drug for prescription? & 15 & 85 \\
- Do you inform the patient regarding disease, drug therapy, regular & 99.5 & 0.5 \\
\hline follow up and monitoring of drug therapy? & & \\
\hline
\end{tabular}

RUM: Rational use of medicine, P-drug: Personal drug, STEP: Safety, Tolerability, Efficacy, Price. 
Table 3: Attitude \& practice of interns \& residents about different aspects of RUM ( $n=200)$

\begin{tabular}{lcc}
\multicolumn{1}{c}{ Questions/ statements } & Response & Percentage \\
\hline - How often do you prescribe essential & Always & 2.5 \\
medicines? & Frequently & 83.5 \\
& Occasionally & 14 \\
- Are you aware of the adverse effects, & Always & 9 \\
interactions and contraindications of the & Frequently & 86 \\
drugs you prescribe? & Occasionally & 5 \\
& Generic name & 33.5 \\
- What do you prefer to write in a prescription & Trade name & 5 \\
slip? & Both & 61.5 \\
& New drug & 9.5 \\
- What do you prefer to prescribe a new or old & Old drug & 8 \\
drug? & Both & 82.5 \\
\hline
\end{tabular}

Table 4: Relationship between various variables and practice of RUM

\begin{tabular}{|c|c|c|c|c|c|c|}
\hline \multirow[t]{2}{*}{ Variables } & \multicolumn{2}{|c|}{ Prescribing EM ( $n=172)$} & \multicolumn{2}{|c|}{ Practicing RUM $(n=190)$} & \multicolumn{2}{|c|}{ Practicing P-drug $(n=59)$} \\
\hline & $\begin{array}{l}\text { No. of } \\
\text { respondents }\end{array}$ & $\mathrm{P}$ value & $\begin{array}{l}\text { No. of } \\
\text { respondents }\end{array}$ & $\mathrm{P}$ value & $\begin{array}{c}\text { No. of } \\
\text { respondents }\end{array}$ & $P$ value \\
\hline & Gender & & & & & \\
\hline Male & 110 & \multirow{2}{*}{$<0.0001$} & 119 & \multirow{2}{*}{$<0.0001$} & 33 & \multirow{2}{*}{0.39} \\
\hline \multirow[t]{2}{*}{ Female } & 62 & & 71 & & 26 & \\
\hline & Qualification & & & & & \\
\hline Intern & 86 & \multirow{2}{*}{1} & 94 & \multirow{2}{*}{0.9} & 36 & \multirow{2}{*}{0.09} \\
\hline Resident & 86 & & 96 & & 23 & \\
\hline
\end{tabular}

Fishers exact test; $\mathrm{p}<0.001$ (statistically highly significant) ; EM: Essential medicine, RUM: Rational use of medicine, P-drug: Personal drug

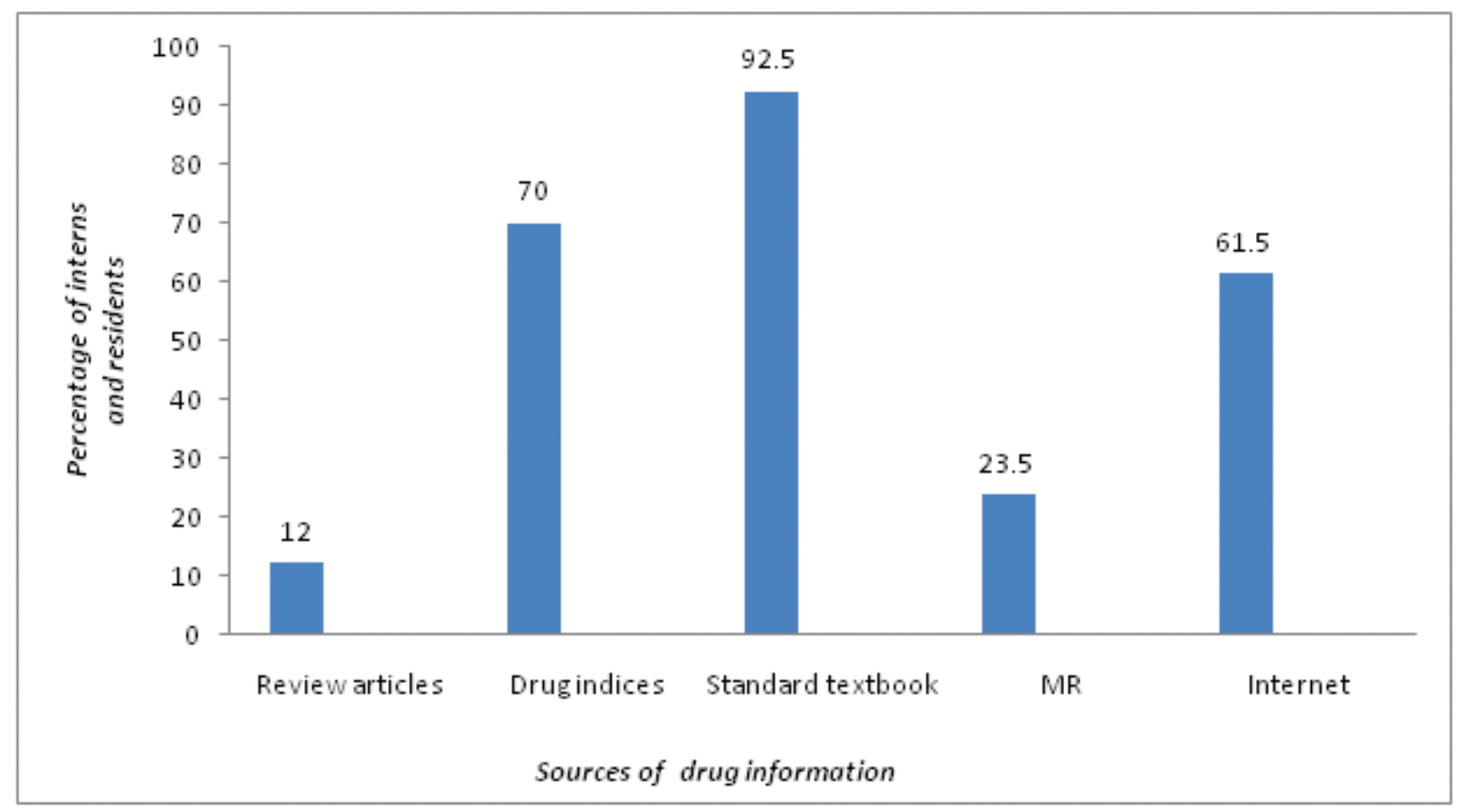

Figure 1: Sources of drug information preferred by intern and resident doctors 
Ironically, only $4 \%$ of the respondents knew the exact number of drugs in the NLEMI and none was able to quantify the fixed dose combination in NLEMI. The findings are similar to the previous study conducted by Mahajan et al. ${ }^{10}$ This clearly indicates lack of measures to update professional knowledge. Regarding EM, not only selection but also its appropriate use is necessary for upgrading quality of health care. ${ }^{11}$ Some studies have reported improvement in the quality of health care following use of NLEM and standard treatment guidelines. ${ }^{12}$ Hence, it is essential to adopt measures that will encourage their use.

In the present study, it is encouraging to know that majority of respondents were aware of RUM, but despite of the large claim made by them only $33.3 \%$ preferred to prescribe medicines by generic name. Majority of the respondents choose to prescribe by brand name as well as generic name. Various studies have revealed that prescribing medicines by brand name has become a routine practice. ${ }^{13,14}$ Prescribing by generic name should be encouraged at an early stage of medical practice to promote RUM. It is encouraging to know that almost all the respondents were always aware of the ingredients of the drug prescribed and they inform the patient regarding disease, drug therapy, and regular follow-up and monitoring of drug therapy. Similarly, awareness of the adverse effects, interactions and contraindications of the prescribed drugs was seen in majority of the respondents. Lack of knowledge regarding adverse effects and interactions can lead to iatrogenic diseases causing more hospital admission and loss of resources. ${ }^{10}$ In this study, the percentage of respondents who are aware of P-drug concept and practicing it, is less (32\% and 15.5\%). This may be because of the fact that P-drug concept is rather a new concept and in India it has started gaining importance in the last few years. ${ }^{15}$ Even though medical students are exposed to this in their pharmacology curriculum during MBBS, lack of knowledge regarding $\mathrm{P}$-drug concept indicates that the P-drug concept has remained confined to pharmacology and has not become popular among clinicians. Involvement of clinicians is vital if the P-drug concept is to succeed. A problem-based learning session for teachers in medical colleges needs to be organized.

When asked to name the sources of drug information used by the respondents, majority of them admitted to rely on information from standard textbooks which is a welcome sign in clinical practice and shows that their prescribing decision are not influenced by medical representatives (MR). Heavy reliability on MRs from different pharmaceutical companies for drug information is often biased and points to clearcut preference towards the market-driven forces leading to irrational prescription behavior and irrational use of medicines. In one study, physicians admitted that their prescribing decision are influenced by $\mathrm{MR}$ and they are bound to prescribe certain medicine at the cost of getting some incentives in the form of free samples, gifts or various kinds of supports. ${ }^{16}$ In our study, there was no significant difference in interns and residents regarding prescribing EM, practicing RUM, and P-drug. Interestingly, the numbers of respondents prescribingEM and practicing RUM were significantly higher in men as compared to women. In contrast to this finding, one study has reported that the concept of RUM was significantly more practiced by females as compared to males. ${ }^{10}$ Though, it is now a well-accepted fact that RUM is an important issue and that doctors are the major prescribers of medicines, teaching of RUM is not given much importance in most of the medical colleges. ${ }^{6}$ This can be considered as a major cause of errors in prescribing with its adverse consequences subsequently. ${ }^{17,18}$ Therefore, sincere efforts are required to promote RUM among clinicians to avoid irrational prescribing. WHO has suggested future strategy and directions regarding RUM like close coordination between process for the development of standard treatment guidelines and efforts to improve quality use of medicine, continued emphasis on the inclusion of EM concept in undergraduate and post-graduate medical curricula and emphasis on the effective utilization of drug and therapeutic committees at regional and district levels. ${ }^{19}$

In conclusion, it is encouraging finding that higher percentages of respondents were aware about EM and also prescribed it. But level of understanding related to P-drug concept and existence of EML are much below par. Considering the fact that respondents are future prescribers they should be aware of all aspects about RUM and improper knowledge in certain areas of RUM is a matter of concern that needs to be addressed. Although the concept of RUM is included in undergraduate curriculum more vigorous training regarding RUM is required to strengthen the mechanism for continuing professional development of clinicians to update their knowledge and skills to prescribe rationally.

\section{REFERENCES}

1. World Health Organization: Selection and rational use of medicines. Available from: http://www.who.int/mediacentre/ factsheets/fs338/en/.

2. Rational use of drugs-Report of the Conference of Experts Nairobi. 1985

3. Holloway K. Promoting rational use of medicines. Contact a publication of world council of churches. 2006;183:2-3.

4. The Selection of Essential Medicines-Perspectives WHO policies. 2002;1-6.

5. National list of essential medicines of India 2011 [Internet]. Available from: http://www.cdsco.nic.in/

6. Manikandan S, Gitanjali B. National list of essential medicines of India: The way forward. J Postgr Med. 2012;58(1):68-72

7. De Vries TP, Henning RH, Horgerzeil HV, Fresle HV. World Health Organization: Guide to good prescribing. Geneva: WHO. 1994;14-8.

8. Sontakke SD, Budania RJ, Paranjape SG. Evaluation of knowledge, attitude and behavior about rational use of medicines in second year medical students. IJBCP. 2013;2(5):617-21.

9. Aronson JK. A prescription for better prescribing. $\mathrm{Br} \mathrm{J}$ Clin Pharmacol. 2006;61(5):487-91.

10. Mahajan R, Singh NR, Singh J, Dixit A, Jain A, Gupta A. Current scenario of attitude and knowledge of physicians about rational prescription: A novel crosssectional study. J Pharm Bioalln Sci. 2010;2(2):132-6.
11. Kar SS, Pradhan HS, Mohanta G. Concept of Essential Medicines and Rational Use in Public Health. Indian J Community Med. 2010;35(1):10-3.

12. Hogerzeil HV. The concept of essential medicines :lesson for rich countries BMJ. 2004;329:(7475)1169-72

13. Rathod R, Rathod A, Gupta VK, AhmedT, Jha RK, Gaikwad N. Audit in Dermatology for Rational Prescribing. RJPBCS. 2012;3(3):518-24.

14. Abidi A, Gupta S, Kansal S. Prescription auditing and drug utilization pattern in a tertiary care teaching hospital of western UP. IJBCP. 2012;1(3):184-90.

15. Parmar DM, Jadhav S. The concept of personal drugs in the undergraduate pharmacology practical curriculum. Indian JPharmacol. 2007;39(3):165-7.

16. Al-areefi MA, Hassali MA, Izham M. Physicians perceptions of medical representative visits in Yemen: a qualitative study. BMC Health Serv Res. 2013;13(1):1. Available from: BMC Health Services Research

17. Bajait CS, Pimpalkhute SA, Sontakke SD, Dakhale GN, Jaiswal KM. Evaluation of knowledge, attitude and practice of rational use of medicines among clinicians in a tertiary care teaching hospital. Int $\mathrm{J}$ Nutr Pharmacol Neurol Dis. 2014;4(3):153-7.

18. Maxwell S, Walley T, Ferner R. Using drugs safely. BMJ. 2002;324(7343):930-1.

19. The selection and use of Essential medicines-Report of the WHO expert committee. Geneva:WHO. 2011. 